Supplement of Ocean Sci., 15, 147-159, 2019 https://doi.org/10.5194/os-15-147-2019-supplement (C) Author(s) 2019. This work is distributed under the Creative Commons Attribution 4.0 License.

(c) (1)

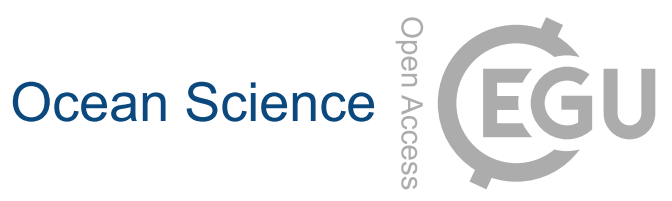

Supplement of

\title{
The impact of sea-level rise on tidal characteristics around Australia
}

Alexander Harker et al.

Correspondence to: Alexander Harker (harker@igg.uni-bonn.de)

The copyright of individual parts of the supplement might differ from the CC BY 4.0 License. 


\section{Introduction}

The supporting information provides additional figures and descriptions to illustrate the behaviour and validation of the $\mathrm{K}_{1}$ constituent, and for the comparison of the result of implementing sea level rise through either a domain-wide uniform depth increase or through extrapolated sea-level trend patterns as observed by satellite altimetry.

\section{Figures}

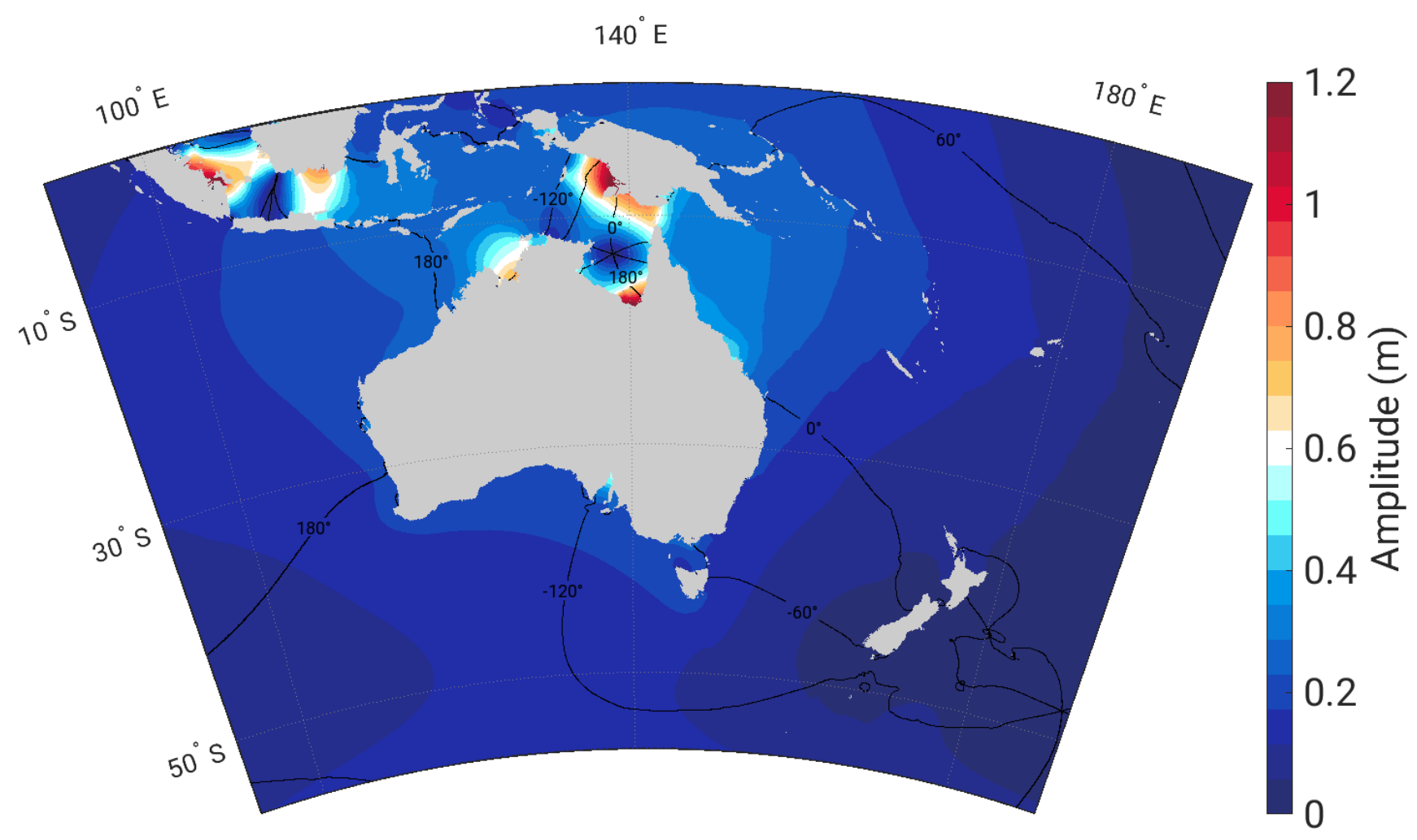

Figure S1 - Co-tidal chart of the $\mathrm{K}_{1}$ constituent amplitude for the control simulation. Black lines represent co-phase lines with $60^{\circ}$ separation, with some lines labelled with their Greenwich phase lag. 

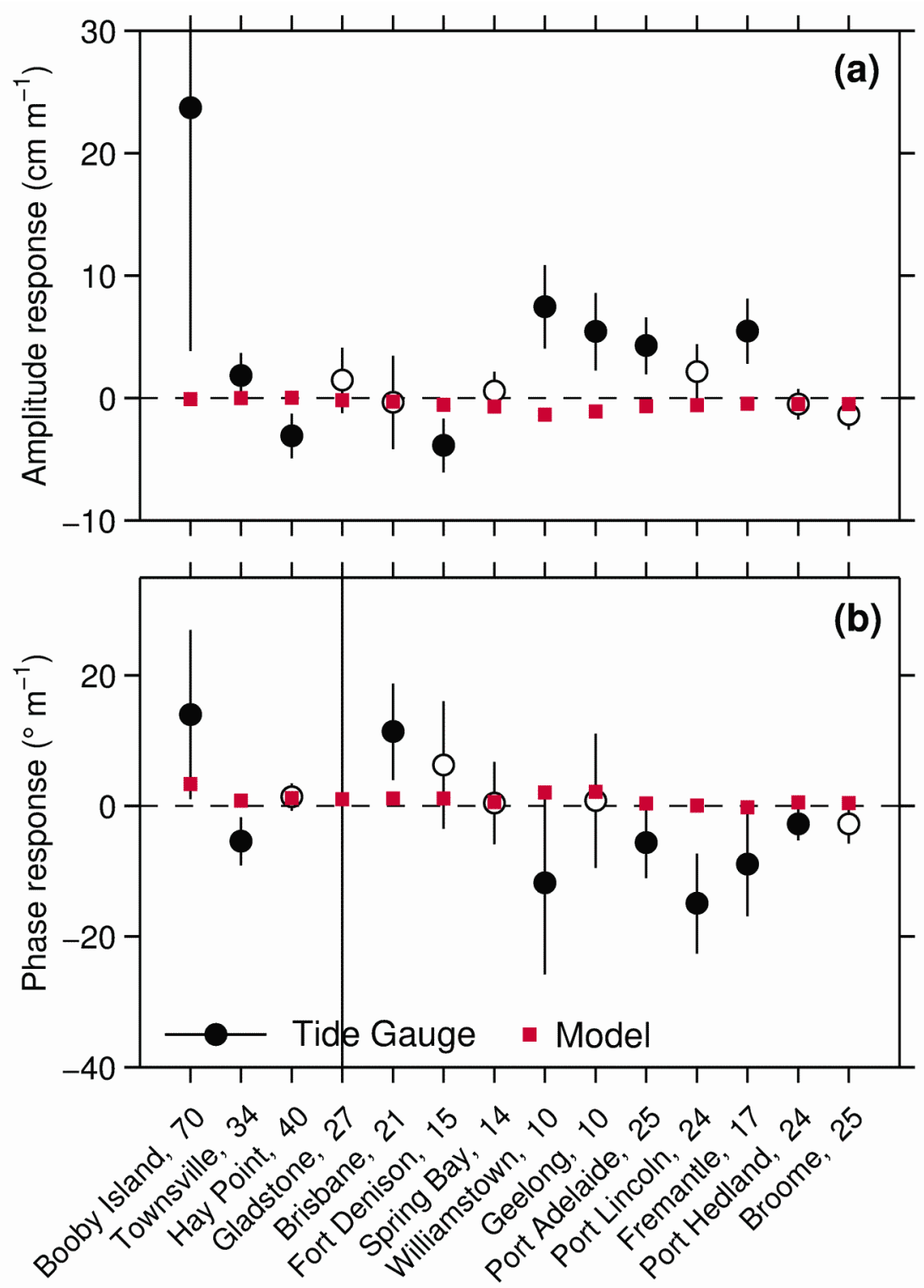

Figure S2 - Observed and modeled $\mathrm{K}_{1}$ response coefficients in (a) amplitude and (b) phase lag per meter of SLR. Model values (red squares) are based on the $1 \mathrm{~m}$ FL simulations, while tide gauge estimates at 14 out of 24 locations are shown in black. Error bars correspond to two standard deviations, propagated from the trend analyses of sea level and annual tidal estimates of $\mathrm{K}_{1}$. Stations with insignificant phase trends (at the $95 \%$ confidence level) are shown as white markers in panel (b). Numbers at the end of the station labeling indicate mean observed $\mathrm{K}_{1}$ amplitudes (cm). 


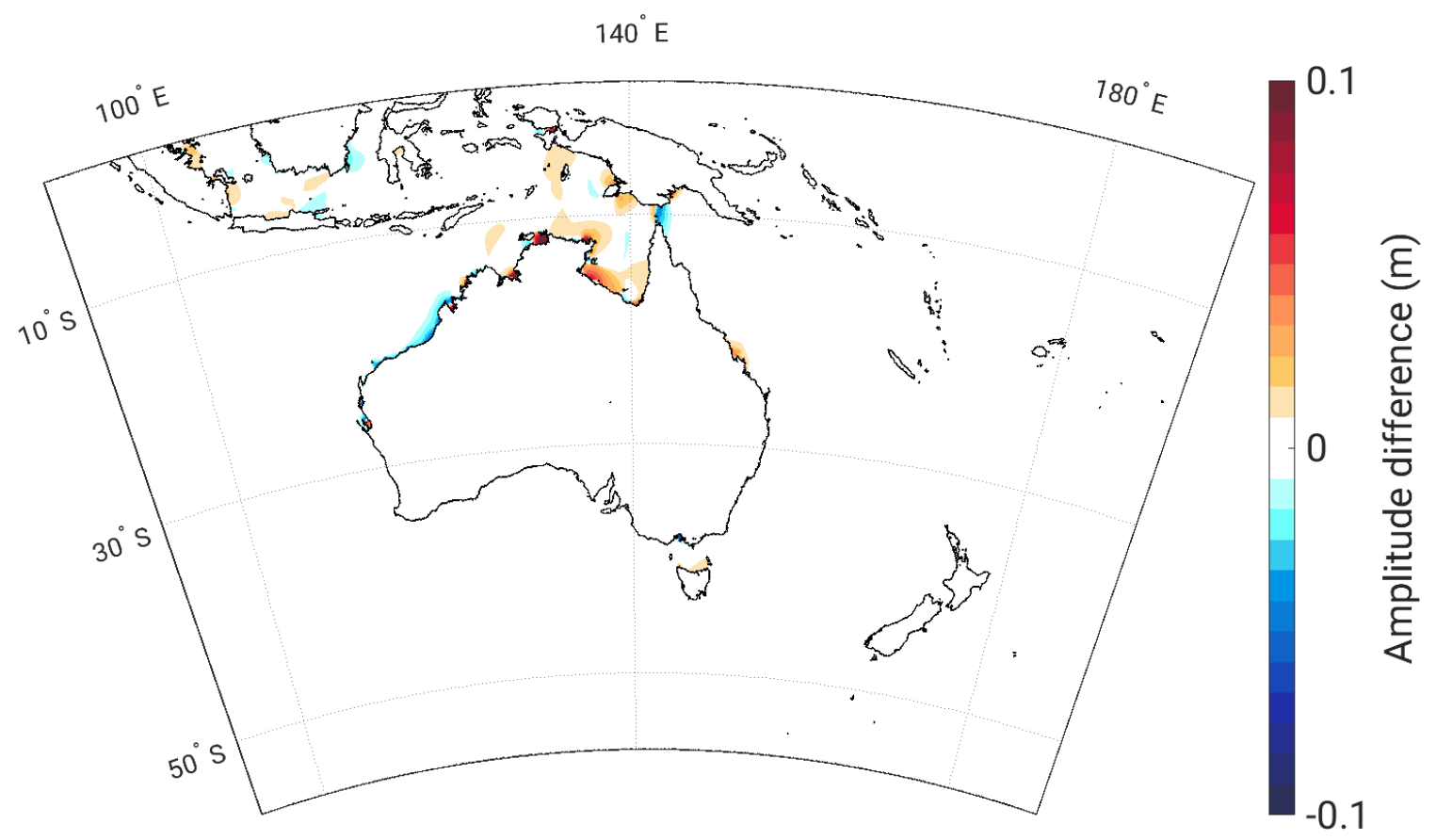

Figure S3 - Difference in $\mathrm{M}_{2}$ amplitude between a simulation with $1 \mathrm{~m}$ uniform sea-level rise and a simulation with $1 \mathrm{~m}$ sea-level rise extrapolated from the sea level trend patterns as observed by satellite altimetry. The major differences occur along the north coast of Australia and in the Gulf of Carpentaria. In this region sea-level trends were missing in the satellite data, and had to be interpolated. In the remainder of the domain there is little or no difference between the simulations. 